\title{
Remarks on Some Recent Fixed Point Results on Quaternion-Valued Metric Spaces
}

\author{
Ravi P. Agarwal, ${ }^{1,2}$ Hamed H. Alsulami, ${ }^{3}$ Erdal Karapınar, ${ }^{3,4}$ and Farshid Khojasteh ${ }^{5}$ \\ ${ }^{1}$ Department of Mathematics, Texas A\&M University-Kingsville, MSC 172, Rhode Hall 217B, Kingsville, TX 78363-8202, USA \\ ${ }^{2}$ Department of Mathematics, Faculty of Science, King Abdulaziz University, Jeddah 21589, Saudi Arabia \\ ${ }^{3}$ Nonlinear Analysis and Applied Mathematics Research Group (NAAM), King Abdulaziz University, Jeddah, Saudi Arabia \\ ${ }^{4}$ Department of Mathematics, Atilim University, Incek, 06836 Ankara, Turkey \\ ${ }^{5}$ Department of Mathematics, Islamic Azad University, Arak Branch, Arak, Iran
}

Correspondence should be addressed to Erdal Karapınar; erdalkarapinar@yahoo.com

Received 17 March 2014; Accepted 18 April 2014; Published 21 May 2014

Academic Editor: Wei-Shih Du

Copyright (c) 2014 Ravi P. Agarwal et al. This is an open access article distributed under the Creative Commons Attribution License, which permits unrestricted use, distribution, and reproduction in any medium, provided the original work is properly cited.

\begin{abstract}
Very recently, Ahmed et al. introduced the notion of quaternion-valued metric as a generalization of metric and proved a common fixed point theorem in the context of quaternion-valued metric space. In this paper, we will show that the quaternion-valued metric spaces are subspaces of cone metric spaces. Consequently, the fixed point results in such spaces can be derived as a consequence of the corresponding existing fixed point result in the setting cone metric spaces.
\end{abstract}

\section{Introduction}

Recently, Azam et al. [1] introduced the notion of complexvalued metric space, as a generalization of Banach-valued metric space which is also known as a cone metric space. The authors [1] proved several fixed point theorems in the context of complex-valued metric space. Inspired from these results, Ahmed et al. [2] defined the concept of quaternionvalued metric space, as a generalization of complex-valued metric space, and proved a common fixed point theorem in the context of such spaces.

In this paper, we announce that the quaternion-valued metric spaces, introduced by Ahmed et al. [2], are subspaces of cone metric spaces. Consequently, the fixed point results in such spaces can be concluded from the classical versions in cone metric spaces. Consequently, the fixed point results in such spaces can be concluded from the classical versions in cone metric spaces. On the other hand, several results have been reported on the equivalence of cone metric space and metric space; see, for example, [3-9]. In particular, by the help of scalarization function, $\mathrm{Du}$ [3] proved that several fixed point results in the context of cone metric spacecan be concluded from the existing associated results in the setting of metric space. Furthermore, if the cone is normal, then there is a metric induced by Banach-valued metric. Hence, most of the announced fixed point results in the setting cone metric space can be deduced from related existing results in the literature in the context of the metric space.

1.1. Complex-Valued Metric Spaces. First we recall the concept of complex-valued metric space which is given by Azam et al. in [1].

Let $\mathbb{C}$ be the set of complex numbers and $z_{1}, z_{2} \in \mathbb{C}$. Define a partial order $\lesssim$ on $\mathbb{C}$ as follows:

$$
z_{1} \precsim z_{2} \quad \text { iff } \quad \operatorname{Re}\left(z_{1}\right) \leq \operatorname{Re}\left(z_{2}\right), \operatorname{Im}\left(z_{1}\right) \leq \operatorname{Im}\left(z_{2}\right) .
$$

It follows that

$$
z_{1} \precsim z_{2}
$$

if one of the following conditions is satisfied:

$$
\begin{array}{ll}
\left(h_{1}\right) \operatorname{Re}\left(z_{1}\right)=\operatorname{Re}\left(z_{2}\right) ; & \operatorname{Im}\left(z_{1}\right)<\operatorname{Im}\left(z_{2}\right), \\
\left(h_{2}\right) \operatorname{Re}\left(z_{1}\right)<\operatorname{Re}\left(z_{2}\right) ; & \operatorname{Im}\left(z_{1}\right)=\operatorname{Im}\left(z_{2}\right), \\
\left(h_{3}\right) \operatorname{Re}\left(z_{1}\right)<\operatorname{Re}\left(z_{2}\right) ; & \operatorname{Im}\left(z_{1}\right)<\operatorname{Im}\left(z_{2}\right), \\
\left(h_{4}\right) \operatorname{Re}\left(z_{1}\right)=\operatorname{Re}\left(z_{2}\right) ; & \operatorname{Im}\left(z_{1}\right)=\operatorname{Im}\left(z_{2}\right) .
\end{array}
$$


In particular, we will write $z_{1} \preccurlyeq z_{2}$ if $z_{1} \neq z_{2}$ and one of $\left(h_{1}\right)$, $\left(h_{2}\right)$, and $\left(h_{3}\right)$ is satisfied and we will write $z_{1} \prec z_{2}$ if only $\left(h_{3}\right)$ is satisfied. Note that

$$
0 \lesssim z_{1} \lesssim z_{2} \Longrightarrow\left|z_{1}\right|<\left|z_{2}\right|
$$

where $|\cdot|$ represents modulus or magnitude of $z$, and

$$
z_{1} \precsim z_{2}, \quad z_{2} \prec z_{3} \Longrightarrow z_{1} \prec z_{3} .
$$

Definition 1 (see [1]). Let $X$ be a nonempty set. A function $d: X \times X \rightarrow \mathbb{C}$ is called a complex-valued metric on $X$, if it satisfies the following conditions:

$$
\begin{aligned}
& \left(b_{1}\right): 0 \precsim d(x, y) \text { for all } x, y \in X \text { and } d(x, y)=0 \text {, if and } \\
& \quad \text { only if } x=y, \\
& \left(b_{2}\right): d(x, y)=d(y, x) \text {, for all } x, y \in X, \\
& \left(b_{3}\right): d(x, y) \precsim d(x, z)+d(y, z) \text {, for all } x, y, z \in X .
\end{aligned}
$$

Here, the pair $(X, d)$ is called a complex-valued metric space.

Let $\left\{x_{n}\right\}$ be a sequence in $X$ and $\in X$. If for every $c \in \mathbb{C}$, with $0 \prec c$, there is $n_{0} \in \mathbb{N}$ such that, for all $n>n_{0}, d\left(x_{n}, x\right) \prec$ $c$, then $\left\{x_{n}\right\}$ is said to be convergent, $\left\{x_{n}\right\}$ converges to $x$, and $x$ is the limit point of $\left\{x_{n}\right\}$. We denote this by $\lim _{n} x_{n}=x$, or $x_{n} \rightarrow x$, as $n \rightarrow \infty$. If for every $c \in \mathbb{C}$ with $0 \prec c$ there is $n_{0} \in \mathbb{N}$ such that for all $n>n_{0}, d\left(x_{n}, x_{n+m}\right) \prec$ $c$, then $\left\{x_{n}\right\}$ is called a Cauchy sequence in $(X, d)$. If every Cauchy sequence is convergent in $(X, d)$, then $(X, d)$ is called a complete complex-valued metric space.

Lemma 2 (see [1, Lemma 2, Azam et al.]). Let $(X, d)$ be a complex-valued metric space and let $\left\{x_{n}\right\}$ be a sequence in. Then $\left\{x_{n}\right\}$ converges to $x$ if and only if $\left|d\left(x_{n}, x\right)\right| \rightarrow 0$ as $n \rightarrow \infty$.

Lemma 3 (see [1, Lemma 3, Azam et al.]). Let $(X, d)$ be a complex-valued metric space and let $\left\{x_{n}\right\}$ be a sequence in. Then $\left\{x_{n}\right\}$ is a Cauchy sequence if and only if $\left|d\left(x_{n}, x_{n+m}\right)\right| \rightarrow$ 0 as $n \rightarrow \infty$.

1.2. Quaternion Metric Space. Now, we recollect the basic definitions and concept on quaternion-valued metric spaces.

The skew field of quaternion denoted by $\mathbb{H}$ means to write each element $q \in \mathbb{U}$ in the form $q=x_{0}+x_{1} i+x_{2} j+x_{3} k ; x_{n} \in \mathbb{R}$, where $1, i, j$, and $k$ are the basis elements of $\mathbb{H}$ and $n=1,2,3$. For these elements we have the multiplication rules $i^{2}=j^{2}=$ $k^{2}=-1, i j=-j i=k, k j=-j k=-i$, and $k i=-i k=j$. The conjugate element $\bar{q}$ is given by $\bar{q}=x_{0}-x_{1} i-x_{2} j-x_{3} k$.

The quaternion modulus has the form of $|q|=$ $\sqrt{x_{0}^{2}+x_{1}^{2}+x_{2}^{2}+x_{3}^{2}}$. A quaternion $\mathrm{q}$ may be viewed as a fourdimensional vector $\left(x_{0}, x_{1}, x_{2}, x_{3}\right)$.

Define a partial order $\lesssim$ on $\mathbb{M}$ as follows.

$q_{1} \precsim q_{2}$ if and only if $\operatorname{Re}\left(q_{1}\right) \leq \operatorname{Re}\left(q_{2}\right), \operatorname{Im}_{s}\left(q_{1}\right) \leq \operatorname{Im}_{s}\left(q_{2}\right)$, $q_{1}, q_{2} \in \mathbb{U}, s=i, j, k$ where $\operatorname{Im}_{i}=x_{1}, \operatorname{Im}_{j}=x_{2}$, and $\operatorname{Im}_{k}=x_{3}$. It follows that $q_{1} \lesssim q_{2}$ if one of the following conditions holds:

(I) $\operatorname{Re}\left(q_{1}\right)=\operatorname{Re}\left(q_{2}\right) ; \operatorname{Im}_{s_{1}}\left(q_{1}\right)=\operatorname{Im}_{s_{1}}\left(q_{2}\right)$ where $s_{1}=j, k$; $\operatorname{Im}_{i}\left(q_{1}\right)<\operatorname{Im}_{i}\left(q_{2}\right)$
(II) $\operatorname{Re}\left(q_{1}\right)=\operatorname{Re}\left(q_{2}\right) ; \operatorname{Im}_{s_{2}}\left(q_{1}\right)=\operatorname{Im}_{s_{2}}\left(q_{2}\right)$ where $s_{2}=i, k$; $\operatorname{Im}_{j}\left(q_{1}\right)<\operatorname{Im}_{j}\left(q_{2}\right)$,

(III) $\operatorname{Re}\left(q_{1}\right)=\operatorname{Re}\left(q_{2}\right) ; \operatorname{Im}_{s_{3}}\left(q_{1}\right)=\operatorname{Im}_{s_{3}}\left(q_{2}\right)$ where $s_{3}=i, j$; $\operatorname{Im}_{k}\left(q_{1}\right)<\operatorname{Im}_{k}\left(q_{2}\right)$

(IV) $\operatorname{Re}\left(q_{1}\right)=\operatorname{Re}\left(q_{2}\right) ; \operatorname{Im}_{s_{1}}\left(q_{1}\right)<\operatorname{Im}_{s_{1}}\left(q_{2}\right) ; \operatorname{Im}_{i}\left(q_{1}\right)=$ $\operatorname{Im}_{i}\left(q_{2}\right)$,

(V) $\operatorname{Re}\left(q_{1}\right)=\operatorname{Re}\left(q_{2}\right) ; \operatorname{Im}_{s_{2}}\left(q_{1}\right)<\operatorname{Im}_{s_{2}}\left(q_{2}\right) ; \operatorname{Im}_{j}\left(q_{1}\right)=$ $\operatorname{Im}_{j}\left(q_{2}\right)$,

(VI) $\operatorname{Re}\left(q_{1}\right)=\operatorname{Re}\left(q_{2}\right) ; \operatorname{Im}_{s_{3}}\left(q_{1}\right)<\operatorname{Im}_{s_{3}}\left(q_{2}\right) ; \operatorname{Im}_{k}\left(q_{1}\right)=$ $\operatorname{Im}_{k}\left(q_{2}\right)$,

(VII) $\operatorname{Re}\left(q_{1}\right)=\operatorname{Re}\left(q_{2}\right) ; \operatorname{Im}_{s}\left(q_{1}\right)<\operatorname{Im}_{s}\left(q_{2}\right)$,

(VIII) $\operatorname{Re}\left(q_{1}\right)<\operatorname{Re}\left(q_{2}\right) ; \operatorname{Im}_{s}\left(q_{1}\right)=\operatorname{Im}_{s}\left(q_{2}\right)$,

(IX) $\operatorname{Re}\left(q_{1}\right)<\operatorname{Re}\left(q_{2}\right) ; \operatorname{Im}_{s_{1}}\left(q_{1}\right)=\operatorname{Im}_{s_{1}}\left(q_{2}\right) ; \operatorname{Im}_{i}\left(q_{1}\right)<$ $\operatorname{Im}_{i}\left(q_{2}\right)$,

(X) $\operatorname{Re}\left(q_{1}\right)<\operatorname{Re}\left(q_{2}\right) ; \operatorname{Im}_{s_{2}}\left(q_{1}\right)=\operatorname{Im}_{s_{2}}\left(q_{2}\right) ; \operatorname{Im}_{j}\left(q_{1}\right)<$ $\operatorname{Im}_{j}\left(q_{2}\right)$,

(XI) $\operatorname{Re}\left(q_{1}\right)<\operatorname{Re}\left(q_{2}\right) ; \operatorname{Im}_{s_{3}}\left(q_{1}\right)=\operatorname{Im}_{s_{3}}\left(q_{2}\right) ; \operatorname{Im}_{k}\left(q_{1}\right)<$ $\operatorname{Im}_{k}\left(q_{2}\right)$,

(XII) $\operatorname{Re}\left(q_{1}\right)<\operatorname{Re}\left(q_{2}\right) ; \operatorname{Im}_{s_{1}}\left(q_{1}\right)<\operatorname{Im}_{s_{1}}\left(q_{2}\right) ; \operatorname{Im}_{i}\left(q_{1}\right)=$ $\operatorname{Im}_{i}\left(q_{2}\right)$,

(XIII) $\operatorname{Re}\left(q_{1}\right)<\operatorname{Re}\left(q_{2}\right) ; \operatorname{Im}_{s_{2}}\left(q_{1}\right)<\operatorname{Im}_{s_{2}}\left(q_{2}\right) ; \operatorname{Im}_{i}\left(q_{1}\right)=$ $\operatorname{Im}_{i}\left(q_{2}\right)$,

(XIV) $\operatorname{Re}\left(q_{1}\right)<\operatorname{Re}\left(q_{2}\right) ; \operatorname{Im}_{s_{3}}\left(q_{1}\right)<\operatorname{Im}_{s_{3}}\left(q_{2}\right) ; \operatorname{Im}_{i}\left(q_{1}\right)=$ $\operatorname{Im}_{i}\left(q_{2}\right)$,

(XV) $\operatorname{Re}\left(q_{1}\right)<\operatorname{Re}\left(q_{2}\right) ; \operatorname{Im}_{s}\left(q_{1}\right)<\operatorname{Im}_{s}\left(q_{2}\right)$,

(XVI) $\operatorname{Re}\left(q_{1}\right)=\operatorname{Re}\left(q_{2}\right) ; \operatorname{Im}_{s}\left(q_{1}\right)=\operatorname{Im}_{s}\left(q_{2}\right)$.

Remark 4. In particular, we write $q_{1} \lesssim q_{2}$ if $q_{1} \neq q_{2}$ and one from (I) to (XVI) is satisfied. Also, we will write $q_{1}<q_{2}$ if only (XV) is satisfied. It should be remarked that

$$
q_{1} \lesssim q_{2} \Longrightarrow\left|q_{1}\right| \leq\left|q_{2}\right| \text {. }
$$

Ahmed et al. [2] introduced the definition of the quaternion-valued metric space as follows.

Definition 5. Let $X$ be a nonempty set. A function $d_{\llbracket \square}: X \times$ $X \rightarrow \mathbb{W}$ is called a quaternion-valued metric on $X$, if it satisfies the following conditions:

$$
\begin{aligned}
& \left(d_{1}\right): 0 \lesssim d_{\mathbb{\sharp}}(x, y) 0 \text { for all } x, y \in X \text { and } d_{\mathbb{\square}}(x, y)=0 \text {, if and } \\
& \text { only if, } x=y \text {, } \\
& \left(d_{2}\right): d_{\mathbb{\square}}(x, y)=d_{\mathbb{\sharp}}(y, x) \text {, for all } x, y \in X \text {, } \\
& \left(d_{3}\right): d_{\mathbb{\sharp}}(x, y) \lesssim d_{\mathbb{\sharp}}(x, z)+d_{\mathbb{\sharp}}(y, z) \text {, for all } x, y, z \in X \text {. }
\end{aligned}
$$

Then, $\left(X, d_{\mathbb{q}}\right)$ is called a quaternion-valued metric space.

Let $\left\{x_{n}\right\}$ be a sequence in $X$ and $\in X$. If for every $c \in \mathbb{C}$, with $0<c$, there is $n_{0} \in \mathbb{N}$ such that, for all $n>n_{0}, d_{\mathbb{\square}}\left(x_{n}, x\right)<$ $c$, then $\left\{x_{n}\right\}$ is said to be convergent, $\left\{x_{n}\right\}$ converges to $x$, and $x$ is the limit point of $\left\{x_{n}\right\}$. We denote this by $\lim _{n} x_{n}=x$, or $x_{n} \rightarrow x$, as $n \rightarrow \infty$. If for every $c \in \mathbb{C}$ with $0<c$ there is $n_{0} \in \mathbb{N}$ such that, for all $n>n_{0}, d_{\mathbb{\square}}\left(x_{n}, x_{n+m}\right)<c$, then $\left\{x_{n}\right\}$ is called a Cauchy sequence in $\left(X, d_{\mathbb{\sharp}}\right)$. If every Cauchy sequence is convergent in $\left(X, d_{\mathbb{U}}\right)$, then $\left(X, d_{\mathbb{\sharp}}\right)$ is called a complete quaternion-valued metric space. 
Lemma 6 (see [2, Lemma 2.1, Ahmed et al.]). Let $(X, d)$ be a quaternion-valued metric space and let $\left\{x_{n}\right\}$ be a sequence in. Then $\left\{x_{n}\right\}$ converges to $x$ if and only if $\left|d\left(x_{n}, x\right)\right| \rightarrow 0$ as $n \rightarrow \infty$.

Lemma 7 (see [2, Lemma 2.2, Ahmed et al.]). Let $\left(X, d_{\mathbb{\sharp}}\right)$ be a quaternion-valued metric space and let $\left\{x_{n}\right\}$ be a sequence in. Then $\left\{x_{n}\right\}$ is a Cauchy sequence if and only if $\left|d_{\mathbb{\square}}\left(x_{n}, x_{n+m}\right)\right| \rightarrow$ 0 as $n \rightarrow \infty$.

1.3. Cone Metric Space. Let $E$ be a real Banach space. A subset $P$ of $E$ is called a cone, if and only if the following holds:

$\left(a_{1}\right): P$ is closed, nonempty, and $P \neq\{0\}$,

$\left(a_{2}\right): a, b \in \mathbb{R}, a, b \geq 0$, and $x, y \in P$ imply that $a x+b y \in P$, $\left(a_{3}\right): x \in P$ and $-x \in P$ imply that $x=0$.

Given a cone $P \subset E$, we define a partial ordering $\leq$ with respect to $P$ by $x \leq y$, if and only if $y-x \in P$. We write $x<y$ to indicate that $x \leq y$ but $x \neq y$, while $x \ll y$ stands for $y-x \in \operatorname{int} P$, where int $P$ denotes the interior of $P$.

The cone $P$ is called normal, if there exist a number $K>0$ such that $0 \leq x \leq y$ implies $\|x\| \leq K\|y\|$, for all $x, y \in E$. The least positive number satisfying this is called the normal constant [10]. It is proved that the normal constant can not be less then 1 (see [11]). For more details on cone metric space, we refer, for example, to [10-16].

In this paper, $E$ denotes a real Banach space, $P$ denotes a cone in $E$ with int $P \neq \emptyset$, and $\leq$ denotes partial ordering with respect to $P$.

Definition 8 (see [10]). Let $X$ be a nonempty set. A function $d: X \times X \rightarrow E$ is called a cone metric on $X$, if it satisfies the following conditions:

$\left(b_{1}\right): d(x, y) \geq 0$ for all $x, y \in X$ and $d(x, y)=0$, if and only if, $x=y$,

$\left(b_{2}\right): d(x, y)=d(y, x)$, for all $x, y \in X$,

$\left(b_{3}\right): d(x, y) \leq d(x, z)+d(y, z)$, for all $x, y, z \in X$.

Then, $(X, d)$ is called a cone metric space.

The following definitions and lemmas have been chosen from $[10,16]$.

Definition 9. Let $(X, d)$ be a cone metric space and let $\left\{x_{n}\right\}_{n \in \mathbb{N}}$ be a sequence in $X$ and $x \in X$. If, for all $c \in E$ with $0 \ll c$, there is $n_{0} \in \mathbb{N}$ such that for all $n>n_{0}, d\left(x_{n}, x_{0}\right) \ll c$, then $\left\{x_{n}\right\}_{n \in \mathbb{N}}$ is said to be convergent, $\left\{x_{n}\right\}_{n \in \mathbb{N}}$ converges to $x$, and $x$ is the limit of $\left\{x_{n}\right\}_{n \in \mathbb{N}}$.

Definition 10. Let $(X, d)$ be a cone metric space and let $\left\{x_{n}\right\}_{n \in \mathbb{N}}$ be a sequence in $X$. If for all $c \in E$ with $0 \ll c$, there is $n_{0} \in \mathbb{N}$ such that, for all $m, n>n_{0}, d\left(x_{n}, x_{m}\right) \ll c$, then $\left\{x_{n}\right\}_{n \in \mathbb{N}}$ is called a Cauchy sequence in $X$.

Definition 11. Let $(X, d)$ be a cone metric space. If every Cauchy sequence is convergent in $X$, then $X$ is called a complete cone metric space.
Definition 12. Let $(X, d)$ be a cone metric space. A self-map $T$ on $X$ is said to be continuous, if $\lim _{n \rightarrow \infty} x_{n}=x$ implies $\lim _{n \rightarrow \infty} T\left(x_{n}\right)=T(x)$ for all sequence $\left\{x_{n}\right\}_{n \in \mathbb{N}}$ in $X$.

Lemma 13. Let $(X, d)$ be a normal cone metric space and let $P$ be a normal cone. Let $\left\{x_{n}\right\}_{n \in \mathbb{N}}$ be a sequence in $X$. Then, $\left\{x_{n}\right\}_{n \in \mathbb{N}}$ converges to $x$, if and only if

$$
\lim _{n \rightarrow \infty} d\left(x_{n}, x\right)=0
$$

Lemma 14. Let $(X, d)$ be a cone metric space and let $\left\{x_{n}\right\}_{n \in \mathbb{N}}$ be a sequence in $X$. If $\left\{x_{n}\right\}_{n \in \mathbb{N}}$ is convergent, then it is a Cauchy sequence.

Lemma 15. Let $(X, d)$ be a cone metric space and let $P$ be a normal cone in $E$. Let $\left\{x_{n}\right\}_{n \in \mathbb{N}}$ be a sequence in $X$. Then, $\left\{x_{n}\right\}_{n \in \mathbb{N}}$ is a Cauchy sequence, if and only if $\lim _{m, n \rightarrow \infty} d\left(x_{m}, x_{n}\right)=0$.

\section{Main Result}

Let $\left(X, d_{\mathbb{\sharp}}\right)$ be a quaternion-valued metric space where $\mathbb{H}$ is the skew field of quaternion number $q$; that is,

$$
\mathbb{W}=\left\{x_{0}+x_{1} i+x_{2} j+x_{3} k:\left(x_{0}, x_{1}, x_{2}, x_{3}\right) \in \mathbb{R}^{4}\right\} .
$$

Define

$$
\begin{gathered}
\mathscr{P}_{\mathbb{G}}=\left\{x_{0}+x_{1} i+x_{2} j+x_{3} k: x_{0} \geq 0,\right. \\
\left.x_{1} \geq 0, x_{2} \geq 0, x_{3} \geq 0\right\} .
\end{gathered}
$$

It is apparent that $\mathscr{P}_{\mathbb{q}} \subset \mathbb{U}$. Assume $\mathbf{0}_{\mathbb{\square}}$ is the zero of $\mathbb{U}$ from now on. Note that $(\mathbb{H},|\cdot|)$ is a real Banach space.

Lemma 16. $\mathscr{P}_{\mathbb{G}}$ is a normal cone in real Banach space $(\mathbb{H},|\cdot|)$.

Proof. Precisely, $\mathscr{P}_{\mathbb{\square}}$ is nonempty, closed and $\mathscr{P}_{\mathbb{\square}} \neq\left(\mathbf{0}_{\mathbb{G}}\right)$. Also for all $\alpha, \beta \in \mathbb{R}^{+}$, and $p, q \in \mathscr{P}_{\mathbb{W}}$ we have $\alpha p+\beta q \in \mathscr{P}_{\mathbb{G}}$ and $\mathscr{P}_{\mathbb{Q}} \cap\left(-\mathscr{P}_{\mathbb{U}}\right)=\left(\mathbf{0}_{\mathbb{U}}\right)$. Notice that the normality of the cone $\mathscr{P}_{\mathbb{a}}$ follows from Remark 4.

Lemma 17. Any quaternion-valued metric space $\left(X, d_{\mathbb{-}}\right)$ is a cone metric space.

Proof. For all $p, q \in \mathbb{W}$ define

$$
p \subseteq q \quad \text { iff } \quad q-p \in \mathscr{P}_{\mathbb{H}} .
$$

$\precsim$ defines a partial ordered on $\mathbb{W}$ and one can easily verify that $\left(X, d_{\mathbb{U}}\right)$ is a cone metric space with respect to $\subseteq$.

Lemma 18. The partial ordered $\lesssim$ defined in Lemma 17 is equivalent to $\subseteq$.

Proof. Assume $p=p_{0}+p_{1} i+p_{2} j+p_{3} k$ and $q=q_{0}+q_{1} i+$ $q_{2} j+q_{3} k . p \subseteq q$, if and only if $q-p \in \mathscr{P}_{\mathbb{H}}$, if and only if $q_{0}-p_{0} \geq 0, q_{1}-p_{1} \geq 0, q_{2}-p_{2} \geq 0$, and $q_{3}-p_{3} \geq 0$. In other words, $\operatorname{Re}(p) \leq \operatorname{Re}(q), \operatorname{Im}_{s}(p) \leq \operatorname{Im}_{s}(q), s=i, j, k$ where $\operatorname{Im}_{i}(p)=p_{1}, \operatorname{Im}_{j}(p)=p_{2}$ and $\operatorname{Im}_{k}(p)=p_{3}$ and $\operatorname{Im}_{i}(q)=q_{1}$, $\operatorname{Im}_{j}(q)=q_{2}$ and $\operatorname{Im}_{k}(q)=q_{3}$, if and only if $p \precsim q$. 
Lemma 19. A sequence $\left\{x_{n}\right\}$ in $\left(X, d_{\mathbb{\square}}\right)$ is convergent in the context of quaternion-valued metric space if and only if $\left\{x_{n}\right\}$ is convergent in the setting of of cone metric space.

Proof. Let $\left\{x_{n}\right\}$ be sequence in $X .\left\{x_{n}\right\}$ converges to $x \in X$ as the concept of quaternion-valued metric space if and only if $\left|d\left(x_{n}, x\right)\right| \rightarrow 0$ as $n \rightarrow \infty$ (see Lemma 6) if and only if $\left\{x_{n}\right\}$ converges to $x$ as the concept of cone metric space by considering $\mathbb{H}$ as the Banach space endowed with the cone $\mathscr{P}_{\mathbb{T}}$ (see Lemma 13).

Let $\left(X, d_{\mathbb{C}}\right)$ be a complex-valued metric space where $\mathbb{C}$ is the skew field of complex number $z$; that is,

$$
\mathbb{C}=\left\{x+y i:(x, y) \in \mathbb{R}^{2}\right\} \text {. }
$$

Define

$$
\mathscr{P}_{\mathbb{C}}=\{x+y i: x \geq 0, y \geq 0\} .
$$

It is apparent that $\mathscr{P}_{\mathbb{C}} \subset \mathbb{C}$. Assume $\mathbf{0}_{\mathbb{C}}$ is the zero of $\mathbb{C}$ from now on. Note that $(\mathbb{C},|\cdot|)$ is a real Banach space.

Lemma 20. $\mathscr{P}_{\mathbb{C}}$ is a normal cone in real Banach space $(\mathbb{C},|\cdot|)$.

Proof. Precisely, $\mathscr{P}_{\mathbb{C}}$ is nonempty, closed and $\mathscr{P}_{\mathbb{C}} \neq\left(\mathbf{0}_{\mathbb{C}}\right)$. Also for all $\alpha, \beta \in \mathbb{R}^{+}$, and $p, q \in \mathscr{P}_{\mathbb{C}}$ we have $\alpha p+\beta q \in \mathscr{P}_{\mathbb{C}}$ and $\mathscr{P}_{\mathbb{C}} \cap\left(-\mathscr{P}_{\mathbb{C}}\right)=\left(\mathbf{0}_{\mathbb{C}}\right)$

Lemma 21. Any complex-valued metric space $\left(X, d_{\mathbb{C}}\right)$ is a cone metric space.

Proof. For all $p, q \in \mathbb{C}$ define

$$
p \subseteq q \quad \text { iff } \quad q-p \in \mathscr{P}_{\mathbb{C}}
$$

$\precsim$ defines a partial ordered on $\mathbb{C}$ and one can easily verify that $\left(X, d_{\mathbb{C}}\right)$ is a cone metric space with respect to $\subseteq$.

Lemma 22. The partial ordered $\lesssim$ defined in Lemma 21 is equivalent to $\subseteq$.

We omitted the proof of Lemma 22 since it is the mimic of the proof Lemma 18.

Lemma 23. A sequence $\left\{x_{n}\right\}$ in $\left(X, d_{\mathbb{C}}\right)$ is convergent as the concept of complex-valued metric space if and only if $\left\{x_{n}\right\}$ is convergent as the concept of cone metric space.

We omit the proof of Lemma 23 above due to Lemma 19.

Definition 24. Let $(X, d)$ be a complete cone metric space. For all $x, y \in X$. A cone metric space $(X, d)$ is said to be metrically convex if $X$ has the property that, for each $x, y \in X$ with $x \neq y$, there exists $z \in X, x \neq y \neq z$ such that

$$
\|d(x, z)+d(z, y)\|=\|d(x, y)\| .
$$

The following lemma finds immediate applications which is straightforward from [17].
Lemma 25. Let $(X, d)$ be a metrically convex quaternionvalued metric space, and let $K$ be a nonempty closed subset of $X$. If $x \in K$ and $y \in K$, then there exists a point $z \notin \partial K$ (where $\partial K$ stands for the boundary of $K$ ) such that

$$
d(x, y)=d(x, z)+d(z, y)
$$

Definition 26. Let $K$ be a nonempty subset of a cone metric space $(X, d)$ and $F, T: K \rightarrow X$. The pair $(F, T)$ is said to be weakly commuting if, for each $x, y \in K$ such that $x=F y$ and $T y \in K$, we have

$$
d(T x, F T y) \leq d(T y, F y)
$$

(see also [12, Hadžić and Gajić]).

Denote $\mathfrak{R}$ by the collection of all continuous and increasing mappings such that $\varphi:[0,+\infty) \rightarrow[0,+\infty)$ such that $\varphi^{-1}(0)=\{0\}$.

Lemma 27. Let $\varphi:[0,+\infty) \rightarrow[0,+\infty)$ be an increasing function. Then,

$$
\varphi\left(t_{n}\right) \longrightarrow 0 \text { implies } t_{n} \longrightarrow 0 .
$$

Proof. Suppose that $\varphi\left(t_{n}\right) \rightarrow 0$ and $t_{n} \nrightarrow 0$. Then there exists $n_{0}>0$ and $\delta>0$ such that $0<\delta<t_{n}$, for all $n \geq n_{0}$. Since $\varphi$ is increasing, we have

$$
0<\varphi(\delta) \leq \varphi\left(t_{n}\right)
$$

and this is a contradiction since $\varphi\left(t_{n}\right) \rightarrow 0$.

Definition 28. Let $K$ be a nonempty subset of a cone metric space $(X, d)$ and let $F, T: K \rightarrow X$ be two mappings. We say that $F$ is generalized $T$-contractive if

$$
\begin{gathered}
\varphi(\|d(F x, F y)\|) \leq b[\varphi(\|d(T x, F x)\|)+\varphi(\|d(T y, F y)\|)] \\
+c \min \{\varphi(\|d(T x, F y)\|) \\
\varphi(\|d(T y, F x)\|)\} .
\end{gathered}
$$

For all $x, y \in K$, with $x \neq y, b, c \geq 0,2 b+c<1$, and let $\varphi \in \mathfrak{R}$.

Proposition 29. Let $(X, d)$ be a complete Banach-valued metric space, which is metrically onvex. Let $K$ be a nonempty closed subset of $X$ and $\varphi \in \Re$, and let $F, T: K \rightarrow X$ be such that $F$ is generalized $T$-contractive. Suppose also we have

(i) $\partial K \subset T K$ and $F K \subset T K$,

(ii) $T x \in \partial K \Rightarrow F x \in K$,

(iii) $F$ and $T$ are weakly commuting,

(iv) $T$ is continuous on $K$.

Then, there exists a unique common fixed point $z$ in $K$ such that $z=T z=F z$. 
Proof. We construct the sequences $\left\{x_{n}\right\}$ and $\left\{y_{n}\right\}$ in the following way.

Let $x \in K$. Then there exists a point $x_{0} \in K$ such that $x=T x_{0}$ as $\partial K \subseteq T K$. From $T x_{0} \in \partial K$ and the implication $T x \in \partial K \Rightarrow F x \in K$, we conclude that $F x_{0} \in K \cap F K \subseteq T K$. Now, let $x_{1} \in K$ be such that

$$
y_{1}=T x_{1}=F x_{0} \in K
$$

Let $y_{2}=F x_{1}$ and assume that $y_{2} \in K$, and then

$$
y_{2} \in K \cap F K \subset T K
$$

which implies that there exists a point $x_{2} \in K$ such that $y_{2}=$ $T x_{2}$. Suppose $y_{2} \notin K$, and then there exists a point $p \in \partial K$ (using Lemma 25), such that

$$
d\left(T x_{1}, p\right)+d\left(p, y_{2}\right)=d\left(T x_{1}, y_{2}\right)
$$

Since $p \in \partial K \subseteq T K$, there exists a point $x_{2} \in K$ such that $p=T x_{2}$ and so

$$
d\left(T x_{1}, T x_{2}\right)+d\left(T x_{2}, y_{2}\right)=d\left(T x_{1}, y_{2}\right)
$$

Let $y_{3}=F x_{2}$. Thus, repeating the forgoing arguments, we obtain two sequences $\left\{x_{n}\right\}$ and $\left\{y_{n}\right\}$ such that

(i) $y_{n+1}=F x_{n}$,

(ii) $y_{n} \in K \Rightarrow y_{n}=T x_{n}$,

(iii) $y_{n} \notin K \Rightarrow T x_{n} \in \partial K$, and

$$
d\left(T x_{n-1}, T x_{n}\right)+d\left(T x_{n}, y_{n}\right)=d\left(T x_{n-1}, y_{n}\right) \text {. }
$$

Denote

$$
\begin{aligned}
& P=\left\{T x_{i} \in\left\{T x_{n}\right\}: T x_{i}=y_{i}\right\}, \\
& Q=\left\{T x_{i} \in\left\{T x_{n}\right\}: T x_{i} \neq y_{i}\right\} .
\end{aligned}
$$

Obviously, the two consecutive terms of $\left\{T x_{n}\right\}$ cannot lie in Q. Let us denote $r_{n}=d\left(T x_{n} ; T x_{n+1}\right)$. We have the following three cases.

Case 1. If $T x_{n}, T x_{n+1} \in P$.

Case 2. If $T x_{n} \in P$ and $T x_{n+1} \in Q$.

Case 3. If $T x_{n} \in Q T x_{n+1} \in P$ and so $T x_{n-1} \in P$.

Proving the above cases are similar to [2, Theorem 3.1]. Also we see that for all $n \in \mathbb{N}$ we get

$$
\varphi\left(\left\|t_{n}\right\|\right) \leq\left(\frac{b+c}{1-b}\right)^{n} \varphi\left(\left\|t_{0}\right\|\right) .
$$

Letting $n \rightarrow \infty$, we have $\varphi\left(\left\|t_{n}\right\|\right) \rightarrow 0$. Since $\varphi \in \mathfrak{R}$, we have $\left\|t_{n}\right\| \rightarrow 0$. So that $\left\{T x_{n}\right\}$ is a Cauchy sequence and hence it converges to a point $z \in K$. Now there exists a subsequence $\left\{T x_{n_{k}}\right\}$ of $\left\{T x_{n}\right\}$ which is contained in $P$. Without loss of generality, we may denote $\left\{T x_{n_{k}}\right\}=\left\{T x_{n}\right\}$. Since $T$ is continuous, $\left\{T T x_{n}\right\}$ converges to $T z$. We are going now to show that $T$ and $F$ have common fixed point $(T z=F z)$. Using the weak commutativity of $T$ and $F$, we obtain that

$$
T x_{n}=F x_{n-1}, \quad T x_{n-1} \in K,
$$

and then

$$
d\left(T T x_{n}, F T x_{n-1}\right) \leq d\left(T x_{n-1}, F x_{n-1}\right)=d\left(T x_{n}, T x_{n-1}\right) .
$$

This implies that

$$
\left\|d\left(T T x_{n}, F T x_{n-1}\right)\right\| \leq\left\|d\left(T x_{n}, T x_{n-1}\right)\right\| .
$$

On letting $n \rightarrow \infty$, we obtain

$$
d\left(T z, F T x_{n-1}\right) \longrightarrow 0
$$

It means that $F T x_{n-1} \rightarrow T z$.

Now, consider

$$
\begin{array}{r}
\varphi\left(\left\|d\left(F T x_{n-1}, F z\right)\right\|\right) \leq b\left[\varphi\left(\left\|d\left(T T x_{n-1}, F T x_{n-1}\right)\right\|\right)\right. \\
+\varphi(\|d(T z, F z)\|)] \\
+c \min \left\{\varphi\left(\left\|d\left(T T x_{n-1}, F z\right)\right\|\right),\right. \\
\left.\varphi\left(\left\|d\left(T z, F T x_{n-1}\right)\right\|\right)\right\} .
\end{array}
$$

Taking limit on both sides of (31) yields

$$
\varphi(\|d(T z, F z)\|) \leq b \varphi(\|d(T z, F z)\|),
$$

which is a contradiction, thus giving $\varphi(\|d(T z, F z)\|)=0$ which implies $\|d(T z, F z)\|=0$, so that $d(T z, F z)=0$ and hence $T z=F z$.

To show that $T z=z$, consider

$$
\begin{aligned}
& \varphi\left(\left\|d\left(T x_{n}, T z\right)\right\|\right)= \varphi\left(\left\|d\left(F x_{n-1}, F z\right)\right\|\right) \\
& \leq b\left[\varphi\left(\left\|d\left(T x_{n-1}, F x_{n-1}\right)\right\|\right)\right. \\
&+\varphi(\|d(T z, F z)\|)] \\
&+c \min \left\{\varphi\left(\left\|d\left(T x_{n-1}, F z\right)\right\|\right),\right. \\
&\left.\varphi\left(\left\|d\left(T z, F x_{n-1}\right)\right\|\right)\right\} .
\end{aligned}
$$

Taking limit on both sides of (33) yields

$$
\varphi(\|d(T z, z)\| \leq c \varphi(\|d(T z, z)\|),
$$

which is a contradiction, thereby giving $\varphi(\|d(z, T z)\|)=0$ which implies $\|d(z, T z)\|=0$, so that $d(z, T z)=0$ and hence $z=T z$. 
Thus, we have shown that $z=T z=F z$, so $z$ is a common fixed point of $F$ and $T$. To show that $z$ is unique, let $w$ be another fixed point of $F$ and $T$, and then

$$
\begin{aligned}
\varphi(\|d(w, z)\|)= & \varphi(\|d(T w, T z)\|) \\
= & \varphi(\|d(F w, F z)\|) \\
\leq & b[\varphi(\|d(T z, F z)\|)+\varphi(\|d(T w, F w)\|)] \\
& +c \min \{\varphi(\|d(T z, F w)\|), \\
& \varphi(\|d(T w, F z)\|)\} \\
= & c \varphi(\|d(w, z)\|),
\end{aligned}
$$

which is a contradiction, therefore giving $\varphi(\|d(w, z)\|)=0$ which implies that $\|d(w, z)\|=0$, so that $d(w, z)=0$; thus, $w=z$.

Theorem 30 (see [2]). Let $\left(X, d_{\mathbb{\sharp}}\right)$ be a complete quaternionvalued metric space which is metrically convex and $K$ a nonempty closed subset of $X$ and $\varphi \in \mathfrak{R}$. Let $F, T: K \rightarrow X$ be such that $F$ is generalized $T$-contractive satisfying the following conditions:

(i) $\partial K \subset T K$ and $F K \subset T K$,

(ii) $T x \in \partial K \Rightarrow F x \in K$,

(iii) $F$ and $T$ are weakly commuting,

(iv) $T$ is continuous on $K$,

and then there exists a unique common fixed point $z$ in $K$ such that $z=T z=F z$.

\section{Theorem 31. Theorem 30 is a consequence of Proposition 29.}

Proof. Let $\left(X, d_{\mathbb{}}\right)$ be a complete quaternion-valued metric space and $K$ a nonempty closed subset of. Then $\left(X, d_{\mathbb{\square}}\right)$ is a complete cone-valued metric space with cone $\mathscr{P}_{\mathbb{1}-1}=\left\{x_{0}+\right.$ $\left.x_{1} i+x_{2} j+x_{3} k: x_{0} \geq 0, x_{1} \geq 0, x_{2} \geq 0, x_{3} \geq 0\right\}$. Further, we have that $F$ is generalized $T$-contractive in cone metric space if and only if $F$ is generalized $T$-contractive in quaternion metric space. The rest follows from Proposition 29.

\section{Further Comment on Cone Metric Spaces}

3.1. By Using a Scalarization Function. In 2010, Du [3] introduced the notion of TVS-valued metric space, also known as TVS-cone metric space (TVS-CMS), as a real generalization of Banach-valued metric space. Let $Y$ be a locally convex Hausdorff t.v.s. with its zero vector $\theta, K$ a proper, closed, convex pointed cone in $Y$ with $K \neq \emptyset, e \in \operatorname{int}(K)$, and $\precsim_{K}$ a partial ordering with respect to $K$.

Definition 32 (see [3]). Let $X$ be a nonempty set. Suppose that a vector-valued function $p: X \times X \rightarrow Y$ satisfies the following:

$$
\begin{aligned}
& \left(c_{1}\right): \theta \preccurlyeq_{K} p(x, y) \text { for all } x, y \in X \text { and } p(x, y)=\theta \text { if and only } \\
& \quad \text { if } x=y,
\end{aligned}
$$

$$
\begin{aligned}
& \left(c_{2}\right): p(x, y)=p(y, x) \text { for all } x, y \in X, \\
& \left(c_{3}\right): p(x, y) \precsim_{K} p(x, z)+p(z, y) \text {, forall } x, y, z \in X .
\end{aligned}
$$

Then, the function $p$ is called TVS-cone metric on $X$. Furthermore, the pair $(X, p)$ is called a TVS-cone metric space (in short, TVS-CMS).

On his paper, Du [3] concluded that, for a TVS-valued metric space $(X, p)$, one can define a function $d_{p}: X \times X \rightarrow$ $[0, \infty)$ by $d_{p}=\xi_{e} \circ p$ forming a metric, where $\xi_{e}: Y \rightarrow \mathbb{R}$, defined by

$$
\xi_{e}(y)=\inf \{r \in \mathbb{R}: y \in r e-K\}, \quad \forall y \in Y,
$$

is a nonlinear scalarization function (see e.g., [18-20]). In this part, whenever we write $\lesssim$, we mean $\precsim_{K}$.

Proposition 33 (see $[3,4])$. Let $(X, p)$ be a TVS-CMS, $x \in X$, and $\left\{x_{n}\right\}_{n \in \mathbb{N}}$ a sequence in $X$. Set $d_{p}=\xi_{e} \circ p$. Then the following statements hold:

(i) $\left\{x_{n}\right\}_{n \in \mathbb{N}}$ converges to $x$ in TVS-CMS $(X, p)$ if and only if $d_{p}\left(x_{n}, x\right) \rightarrow 0$ as $n \rightarrow \infty$,

(ii) $\left\{x_{n}\right\}_{n \in \mathbb{N}}$ is a Cauchy sequence in TVS-CMS $(X, p)$ if and only if $\left\{x_{n}\right\}_{n \in \mathbb{N}}$ is a Cauchy sequence in $\left(X, d_{p}\right)$,

(iii) $(X, p)$ is a complete TVS-CMS if and only if $\left(X, d_{p}\right)$ is a complete metric space.

From Proposition 33, the following result was derived easily.

Proposition 34 (see [3]). Let $(X, p)$ is complete TVS-CMS and $T: X \rightarrow X$ satisfies the contractive condition:

$$
p(T x, T y) \lesssim k p(x, y)
$$

for all $x, y \in X$ and $0 \leq k<1$. Then, $T$ has a unique fixed point in $X$. Moreover, for each $x \in X$, the iterative sequence $\left\{T^{n} x\right\}_{n=1}^{\infty}$ converges to fixed point.

Proposition 35 (see [3]). The Banach contraction principle and Proposition 34 are equivalent.

Definition 36. Let $K$ be a nonempty subset of a metric space $(X, d)$ and let $F, T: K \rightarrow X$ be two mappings. We say that $F$ is generalized $T$-contractive of type $A$ if

$$
\begin{aligned}
\varphi(d(F x, F y)) \leq & b[\varphi(d(T x, F x))+\varphi(d(T y, F y))] \\
& +c \min \{\varphi(d(T x, F y)), \varphi(d(T y, F x))\}
\end{aligned}
$$

For all $x, y \in K$, with $x \neq y, b, c \geq 0,2 b+c<1$, and let $\varphi \in \mathfrak{R}$.

Proposition 37. Let $(X, d)$ be a complete metric space, let $K$ be a nonempty closed subset of $X$ and $\varphi \in \Re$, and let $F, T$ : $K \rightarrow X$ be such that $F$ is generalized $T$-contractive of type $A$. If the following are satisfied:

(i) $\partial K \subset T K$ and $F K \subset T K$,

(ii) $T x \in \partial K \Rightarrow F x \in K$, 
(iii) $F$ and $T$ are weakly commuting,

(iv) $T$ is continuous on $K$,

then there exists a unique common fixed point $z$ in $K$ such that $z=T z=F z$.

We skip the proof of Proposition 37 since it can be derived by the mimic of Proposition 29. On the other hand, regarding Proposition 35, we can conclude that Proposition 37 implies Proposition 29.

\subsection{By Using a Metric-Type Space}

Definition 38 (see, e.g., [5]). Let $X$ be a set. Let $D: X \times X \rightarrow$ $[0, \infty)$ be a function which satisfies

(1) $D(x, y)=0$ if and only if $x=y$,

(2) $D(x, y)=D(y, x)$, for any $x, y \in X$,

(3) $D(x, y) \leq K\left(D\left(x, z_{1}\right)+D\left(z_{2}, z_{3}\right)+\cdots+D\left(z_{n-1}, z_{n}\right)+\right.$ $\left.D\left(z_{n}, y\right)\right)$ for any $x, y, z_{1}, \ldots, z_{n} \in X$,

for some constant $K>0$. The pair $(X, D)$ is called a metrictype space.

Proposition 39. Let $(X, d)$ be a metric cone over the Banach space $E$ with the cone $P$ which is normal with the normal constant $K$. The mapping $D: X \times X \rightarrow[0, \infty)$ defined by $D(x, y)=\|d(x, y)\|$ is a function which satisfies

(1) $D(x, y)=0$ if and only if $x=y$,

(2) $D(x, y)=D(y, x)$, for any $x, y \in X$,

(3) $D(x, y) \leq K\left(D\left(x, z_{1}\right)+D\left(z_{2}, z_{3}\right)+\cdots+D\left(z_{n-1}, z_{n}\right)+\right.$ $\left.D\left(z_{n}, y\right)\right)$ for any $x, y, z_{1}, \ldots, z_{n} \in X$.

Remark 40. In Definition 38, (3), the term $z_{i}$ needs not to be distinct. Hence, metric type space turns into $b$-metric space when we deal with cone metric space (see, e.g., [21, 22]).

Remark 41. Furthermore, by Lemma 20, $\mathscr{P}_{\mathbb{Q}}$ is a normal cone. Hence, some resuls of [2] and Theorem 30, are equivalent to the corresponding results in the context of metric-type space (see also [5]).

\section{Conflict of Interests}

The authors declare that there is no conflict of interests regarding the publication of this paper.

\section{Authors' Contribution}

All authors contributed equally and significantly in writing this paper. All authors read and approved the final paper.

\section{Acknowledgments}

This research was supported by the Deanship of Scientific Research (DSR), King Abdulaziz University, Jeddah, Saudi Arabia. The authors thank the anonymous referees for their remarkable comments, suggestions, and ideas that helped to improve this paper.

\section{References}

[1] A. Azam, B. Fisher, and M. Khan, "Common fixed point theorems in complex valued metric spaces," Numerical Functional Analysis and Optimization, vol. 32, no. 3, pp. 243-253, 2011.

[2] A. E.-S. Ahmed, A. J. Asad, and S. Omran, "Fixed point theorems in quaternion-valued metric spaces," Abstract and Applied Analysis, vol. 2014, Article ID 258985, 9 pages, 2014.

[3] W.-S. Du, "A note on cone metric fixed point theory and its equivalence," Nonlinear Analysis: Theory, Methods \& Applications, vol. 72, no. 5, pp. 2259-2261, 2010.

[4] T. Abdeljawad and E. Karapinar, "A gap in the paper "a note on cone metric fixed point theory and its equivalence" [Nonlinear Anal. 72(5), (2010), 2259-2261]," Gazi University Journal of Science, vol. 24, no. 2, pp. 233-234, 2011.

[5] M. A. Khamsi, "Remarks on cone metric spaces and fixed point theorems of contractive mappings," Fixed Point Theory and Applications, vol. 2010, Article ID 315398, 7 pages, 2010.

[6] A. Amini-Harandi and M. Fakhar, "Fixed point theory in cone metric spaces obtained via the scalarization method," Computers \& Mathematics with Applications, vol. 59, no. 11, pp. 35293534, 2010.

[7] Y. Feng and W. Mao, "The equivalence of cone metric spaces and metric spaces," Fixed Point Theory, vol. 11, no. 2, pp. 259$263,2010$.

[8] S. Janković, Z. Kadelburg, and S. Radenović, "On cone metric spaces: a survey," Nonlinear Analysis: Theory, Methods \& Applications, vol. 74, no. 7, pp. 2591-2601, 2011.

[9] Z. Kadelburg, S. Radenović, and V. Rakočević, "A note on the equivalence of some metric and cone metric fixed point results," Applied Mathematics Letters, vol. 24, no. 3, pp. 370-374, 2011.

[10] L.-G. Huang and X. Zhang, "Cone metric spaces and fixed point theorems of contractive mappings," Journal of Mathematical Analysis and Applications, vol. 332, no. 2, pp. 1468-1476, 2007.

[11] S. Rezapour and R. H. Haghi, "Some notes on the paper 'cone metric spaces and fixed point theorems of contractive mappings"' Journal of Mathematical Analysis and Applications, vol. 345, no. 2, pp. 719-724, 2008.

[12] O. Hadžić and L. Gajić, "Coincidence points for set-valued mappings in convex metric spaces," Univerzitet u Novom Sadu. Zbornik Radova Prirodno-Matematičkog Fakulteta, vol. 16, no. 1, pp. 13-25, 1986.

[13] E. Karapinar, "Couple fixed point theorems for nonlinear contractions in cone metric spaces," Computers \& Mathematics with Applications, vol. 59, no. 12, pp. 3656-3668, 2010.

[14] T. Abdeljawad and E. Karapinar, "Quasicone metric spaces and generalizations of Caristi Kirk's theorem," Fixed Point Theory and Applications, vol. 2009, Article ID 574387, 9 pages, 2009.

[15] E. Karapınar, "Some nonunique fixed point theorems of Ćirić type on cone metric spaces," Abstract and Applied Analysis, vol. 2010, Article ID 123094, 14 pages, 2010.

[16] F. Khojsteh, A. Razani, and S. Moradi, "A fixed point of generalized $T_{F}$-contraction mappings in cone metric spaces," Fixed Point Theory and Applications, vol. 2011, article 14, 2011.

[17] N. A. Assad and W. A. Kirk, "Fixed point theorems for setvalued mappings of contractive type," Pacific Journal of Mathematics, vol. 43, pp. 553-562, 1972.

[18] G.-Y. Chen, X. X. Huang, and X. Q. Yang, Vector Optimization, Springer, Berlin, Germany, 2005.

[19] W.-S. Du, "On some nonlinear problems induced by an abstract maximal element principle," Journal of Mathematical Analysis and Applications, vol. 347, no. 2, pp. 391-399, 2008. 
[20] W.-S. Du, "The existence of cone critical point and common fixed point with applications," Journal of Applied Mathematics, vol. 2011, Article ID 985797, 22 pages, 2011.

[21] H. Aydi, M.-F. Bota, E. Karapınar, and S. Mitrović, "A fixed point theorem for set-valued quasi-contractions in b-metric spaces," Fixed Point Theory and Applications, vol. 2012, article 88, 8 pages, 2012.

[22] H. Aydi, M.-F. Bota, E. Karapinar, and S. Moradi, "A common fixed point for weak $\varphi$-contractions on $b$-metric spaces," Fixed Point Theory, vol. 13, no. 2, pp. 337-346, 2012. 


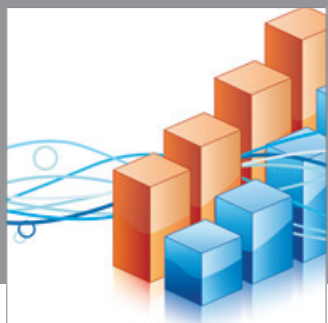

Advances in

Operations Research

mansans

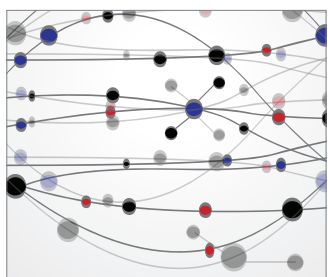

The Scientific World Journal
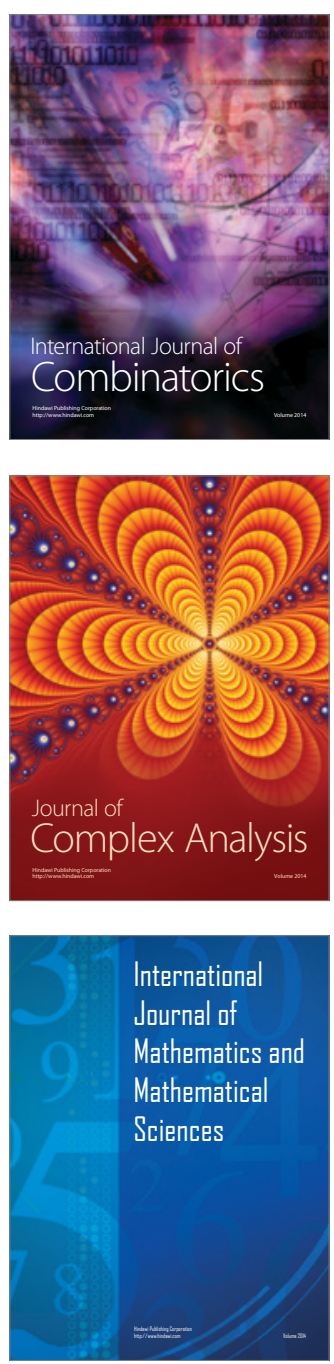
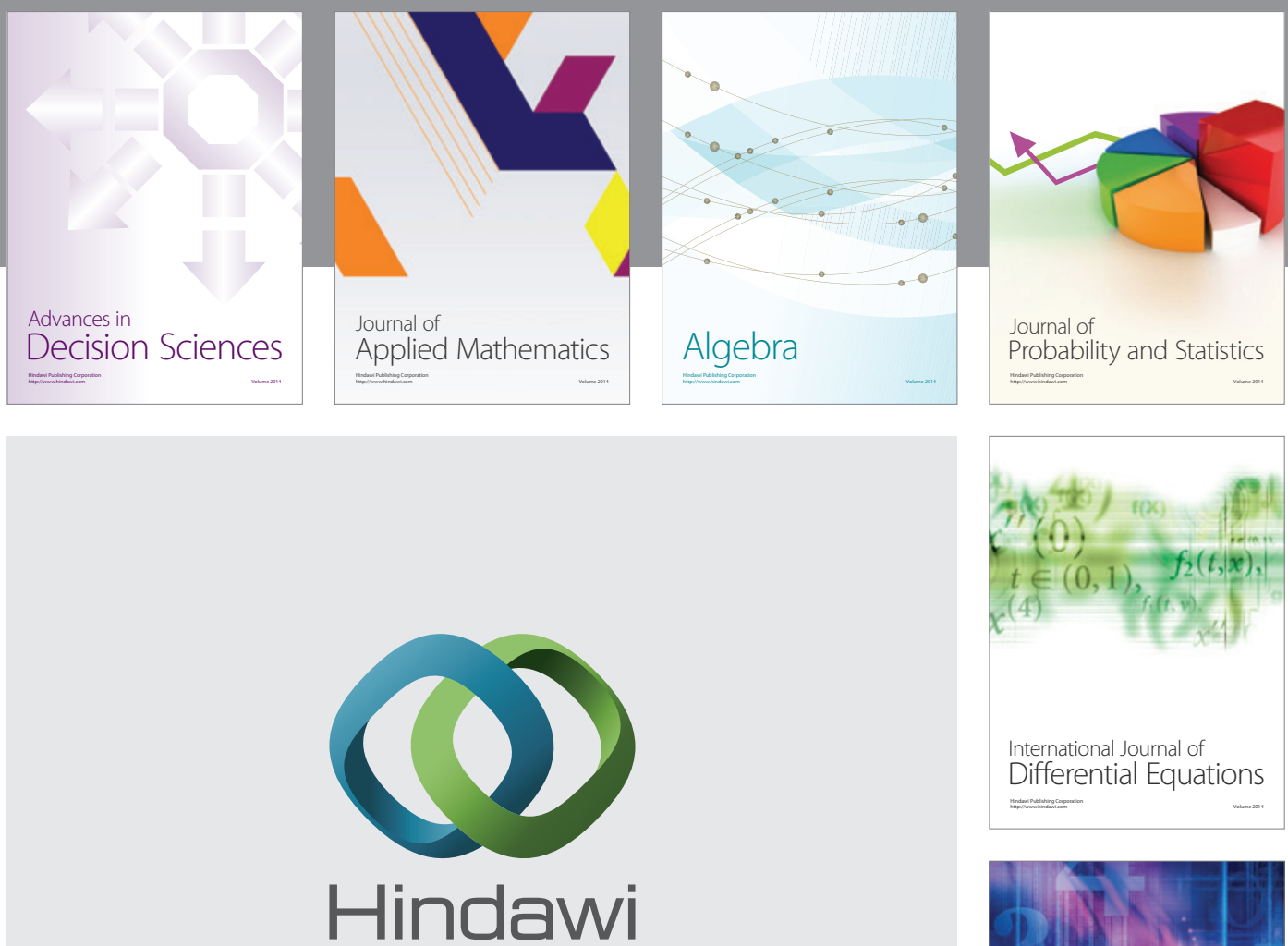

Submit your manuscripts at http://www.hindawi.com
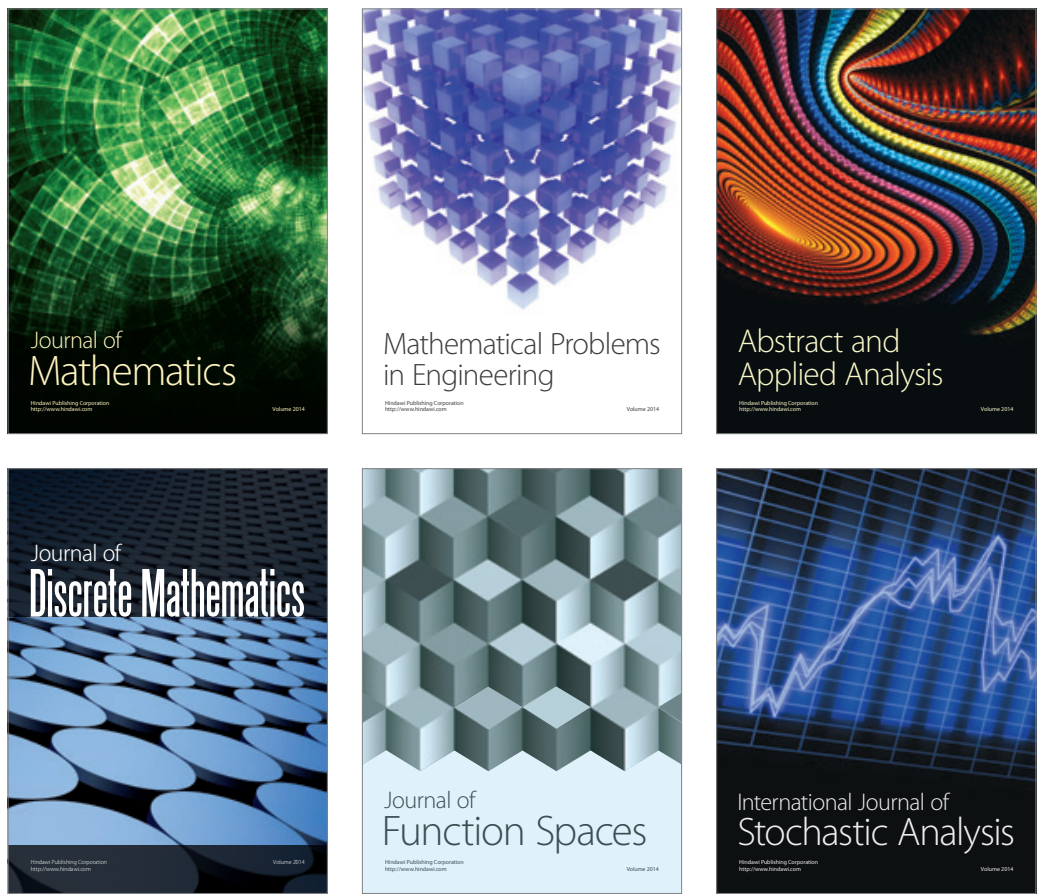

Journal of

Function Spaces

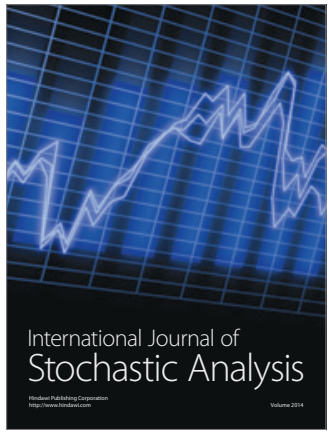

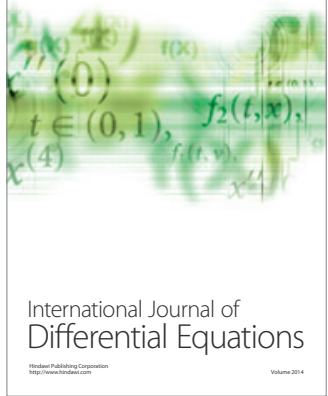
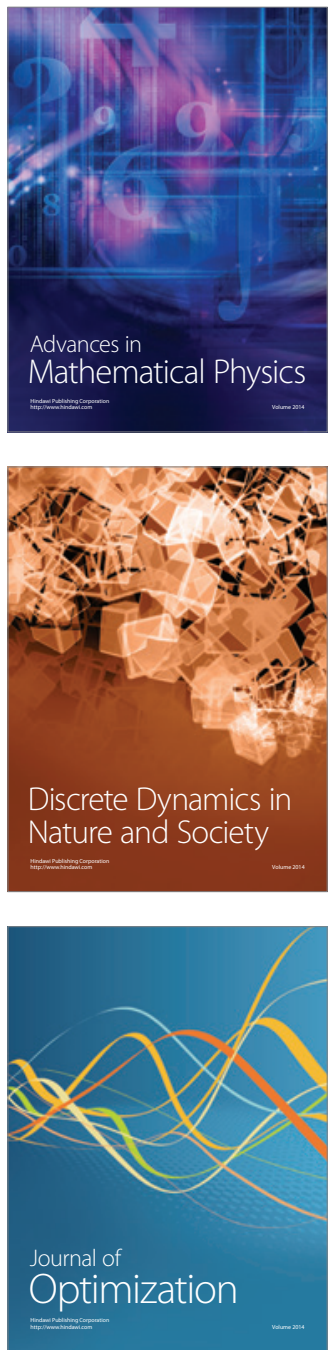